by GOLD, on the basis of their CAT/mMRC scores and GOLD stage/Exacerbation frequency. Using CAT as the symptom grade, we compared patient distribution in the 4 categories using scores between 10 and 20 to determine the CAT threshold at which the distribution of patients in each group is proportional.

Results The proportion of patients in each of the 4 categories was consistent for each symptom score whether risk was assessed by FEV1 or exacerbation number. However the proportions using CAT 10 and $\mathrm{mMRC} 0-1, \geq 2$ were significantly different in each category. When the CAT threshold was changed to 13, the proportions of patients in the four groups were no longer significantly different to those using mMRC.

Conclusion We have demonstrated that in patients with AATD, using CAT score of 13 as the threshold for assessing symptoms results in a similar proportion of patients being categorised into the risk categories. This affects risk assessment and therapeutic choice. Longitudinal follow up and monitoring will enable confirmation of this threshold for patient management.

\section{P189 REDUCED COPD EXACERBATIONS ASSOCIATED WITH ACLIDINIUM BROMIDE VERSUS PLACEBO: A POOLED ANALYSIS OF PHASE III DATA}

doi:10.1136/thoraxjnl-2012-202678.250

'Paul W Jones, ${ }^{2}$ Dave Singh, ${ }^{3}$ Edward Kerwin, ${ }^{4}$ Rosa Lamarca, ${ }^{5}$ Cynthia Caracta, ${ }^{4}$ Esther Garcia Gil. 'St George's, University of London, London, UK; ' ${ }^{2}$ Medicines Evaluation Unit Ltd, Manchester, UK; ${ }^{3}$ Clinical Research Institute, Medford, USA; ${ }^{4}$ Almirall SA, Barcelona, Spain; ${ }^{5}$ Forest Research Institute, Jersey City, New Jersey, USA

Introduction and objective Aclidinium bromide is a novel, longacting, inhaled muscarinic antagonist indicated for the treatment of chronic obstructive pulmonary disease (COPD). COPD is characterised by periodic worsening of symptoms (exacerbations) that are associated with increased morbidity and mortality. Here, we report the results of a pooled analysis of aclidinium on exacerbations.

Methods Data from two Phase III studies (3-month ACCORD COPD I and 6-month ATTAIN) were included in this analysis. Both were designed to evaluate the efficacy and safety of aclidinium 200 $\mu \mathrm{g}$ and $400 \mu \mathrm{g}$ (metered dose) BID versus placebo (primary endpoint: change from baseline in $\mathrm{FEV}_{1}$ ). Adults (aged $\geq 40$ years) with moderate-to-severe COPD, who were current/former smokers with a smoking history $\geq 10$ pack-years, were included. Exacerbations (additional endpoint) were assessed in both studies using healthcare resource utilisation (HCRU) criteria (increase in symptoms for $\geq 2$ consecutive days that required increased medication use or other medical intervention) and, in ATTAIN only, with the Exacerbations of Chronic Pulmonary Disease Tool (EXACT [daily diary card data with exacerbations defined according to the developer's criteria]). Neither study was individually powered to assess treatment differences in exacerbation frequency. In this pooled analysis, exacerbation rate ratios (per patient/year for aclidinium versus placebo) were analyzed using a Poisson regression model corrected for overdispersion; 95\% confidence intervals and p-values were calculated.

Results Data for 1378 patients were included; the majority (62\%) were male with a mean age of approximately 63 years. At baseline, $>60 \%$ of patients were classed as GOLD stage II (moderate), and $31 \%$ reported $\geq 1$ exacerbations in the previous 12 months. In both studies, there was a trend towards relative reduction (approximately $30 \%$ ) in the rate of moderate or severe exacerbations (requiring antibiotic or corticosteroid treatment, or hospitalisation) with both aclidinium doses versus placebo (Figure). A significant reduction in moderate or severe exacerbation rate was observed with aclidinium $400 \mu \mathrm{g}$ versus placebo when data from both studies were pooled ( 0.31 vs 0.44 ; rate ratio $0.71, p=0.01$ ).

Conclusions This pooled analysis provides evidence to support a reduction in moderate or severe COPD exacerbations with aclidinium $200 \mu \mathrm{g}$ and $400 \mu \mathrm{g}$ BID compared with placebo.

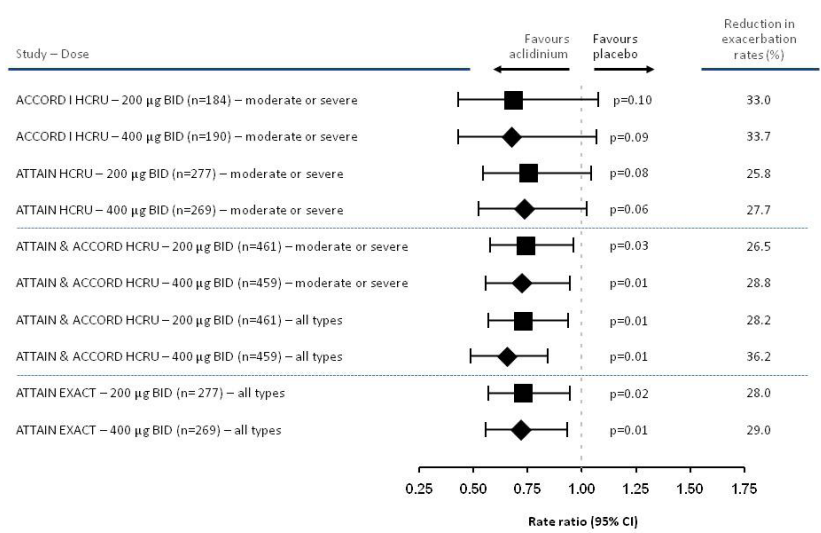

Abstract P189 Figure 1

\section{P190 OVA149 ONCE DAILY PROVIDES SIGNIFICANT IMPROVEMENTS IN LUNG FUNCTION OVER 1 YEAR IN PATIENTS WITH COPD: THE ENLIGHTEN STUDY}

doi:10.1136/thoraxjnl-2012-202678.251

${ }^{1} \mathrm{R}$ Dahl, ${ }^{2} \mathrm{~K}$ Chapman, ${ }^{3} \mathrm{M}$ Rudolf, ${ }^{4} \mathrm{R}$ Mehta, ${ }^{5} \mathrm{P}$ Kho, ${ }^{6} \mathrm{~V}$ Alagappan, ${ }^{6}$ Berhane, ${ }^{6} \mathrm{H}$ Chen, ${ }^{6} \mathrm{D}$ Banerji. 'Department of Respiratory Diseases, Aarhus University Hospital, Aarhus, Denmark; ${ }^{2}$ Asthma and Airway Centre, University Health Network, Toronto Western Hospital, Toronto, Canada; ${ }^{3}$ Department of Respiratory Medicine, Ealing Hospital NHS Trust and Imperial College, London, UK; ${ }^{4}$ Allergy and Asthma Care, Allergy and Asthma Care and Research Centre, Indore, India; ${ }^{5}$ Novartis Horsham Research Center, Horsham, West Sussex, UK, ${ }^{6}$ Novartis Pharmaceuticals Corporation, East Hanover, NJ, USA

Introduction QVA149 is a novel inhaled once-daily dual bronchodilator, containing a fixed-dose combination of the long-acting $\beta_{2}$-agonist indacaterol and the long-acting muscarinic antagonist NVA237 (glycopyrronium) in development for the treatment of COPD. This study evaluated the long-term effect of QVA149 on lung function in patients with COPD.

Methods This was a multicentre, double-blind, parallel group, placebo-controlled study in which patients with moderate-tosevere COPD were randomised (2:1) to receive OVA149 $(110 / 50 \mu \mathrm{g})$ or placebo once daily via the Breezhaler ${ }^{\circledR}$ device for 52 weeks. Treatment was taken in the morning at the same time of day. Lung function was measured as forced expiratory volume in 1 second $\left(\mathrm{FEV}_{1}\right)$ and forced vital capacity (FVC) at 30 and 60 minutes post-dose at clinic visits over 52 weeks.

Results 339 patients (77\% male, mean age 63 years; mean postsalbutamol $\mathrm{FEV}_{1} 57 \%$ predicted, $\mathrm{FEV}_{1} / \mathrm{FVC} 54 \%$ ) were randomised to receive QVA149 ( $n=226)$ or placebo $(n=113) ; 86 \%$ and $79 \%$ of patients respectively completed treatment, respectively. OVA149 significantly increased $\mathrm{FEV}_{1}$ and $\mathrm{FVC}$ versus placebo at all assessment points (table).

Conclusion QVA149 once daily provided rapid and clinically meaningful bronchodilation compared with placebo. No tachyphylaxis was observed and the bronchodilator effect was sustained over the 52 week treatment period.

Ronal Dahl: he participated in advisory boards for Novartis, AstraZeneca, Boehringer-Ingelheim, Pfizer, ALK-Abello, UCB, Nycomed, Dainippon and ONO.

Kenneth R Chapman: he holds the GSK-CIHR Research Chair in Respiratory Healthcare Delivery at the University Health Network, has served as a consultant to CSL Behring, GlaxoSmithKline, Novartis, Nycomed (Takeda), and Talecris (Grifols), and has received payment for lectures or service on speakers bureaus from Boehringer-Ingelheim, GlaxoSmithKline, Grifols, Nycomed (Takeda), Family Physicians Airways Group of Canada, Canadian Network for Respiratory Care, and Talecris. 